\title{
Single-Trait Bayesian Analysis of Some Growth Traits in Japanese Quail
}

http://dx.doi.org/10.1590/1516-635x160251-56

\section{-Author(s)}

Karaman E

Firat MZI

Narinc $D^{\prime}$

Akdeniz University, Faculty of Agriculture, Department of Animal Science, Antalya, Turkey.

" Namik Kemal University, Faculty of Veterinary Medicine, Department of Genetics, Tekirdag, Turkey.

\section{Mail Adress}

Corresponding author e-mail address: Prof. Dr. Mehmet Z. Firat

Akdeniz University, Faculty of Agriculture, Department of Animal Science, Antalya, Turkey

E-mail: mziyafirat@gmail.com

\section{nKeywords}

Absolute growth rate, Bayesian, heritability, quail, relative growth rate.

\section{ABSTRACT}

The aim of this study was to estimate the heritability for some growth traits of Japanese quail through the estimation of variance components by Bayesian methodology. For this purpose, 340 progenies of 34 sires were used. Live weight (LW42) and absolute and relative growth rates at 42 days of age (AGR42 and RGR42, respectively) were submitted to single-trait analysis under a sire model. A software (package MCMCglmm) was used for the estimations, and a single chain with 65,000 rounds was run for each trait with a thinning interval of 50. Burn-in was set at 15,000 and inferences were built on posterior samples of 1,000 draws for each trait. All marginal posterior densities were unimodal and marginal posterior distributions of sire variance are slightly skewed to the right. The results of the analyses showed high, moderate, and low heritability of LW42, AGR42, and RGR42, respectively.

\section{INTRODUCTION}

The main contributions on genetic improvement of Japanese quail have been made in the last decades, particularly during the last 30 years. However, most of these studies have concentrated on live-weight at fixed ages, especially 35 and 42 days of age, or on the number of eggs produced. On the other hand, in modern poultry breeding, new traits related to meat yield are of interest. Meat quality traits $(\mathrm{pH}$, color, tenderness, etc.) and body conformation, which are not yet considered in quail breeding, are used in meat-type chicken breeding (Remignon \& Le Bihan-Duval, 2003). Recently, alternative selection criteria have been investigated to increase the efficiency of meat production, such as direct selection for low body fat content or feed conversion ratio or, accompanying these two criteria, selection on the shape of growth curve (Akbas \& Yaylak, 2000; Hyankova et al., 2001). There are some studies proposing that the use of absolute and relative growth rates ( $A G R$ and $R G R$, respectively) derived from fitted growth curves, may affect the achievement of the selection goal (Hyankova et al., 2001; Aggrey, 2004). AGR is the change in live weight per unit of time, whereas RGR is the ratio of the rate of change in body weight required to achieve growth goal at a given age (Aggrey, 2004).

Geneticists have mostly been focused on exposing the underlying genetic structure of the traits which are quantitative in nature and show a great variability. Heritability, as a measure of the response rate of the trait under selection, is one of the most important genetic parameters that measures the genetic variability caused by genetic differences among individuals out of the total variability (Kumar et al., 2004). There are two main approaches to estimate heritability: one based on intrasire regression of offspring on dam (parent-offspring regression) and 
the other based on variance components of full-sib or half-sib analysis. The accuracy of the estimates of variance components is directly related with the choice of data, method, and model (Misztal, 1990).

Methods used to estimate variance components date back from Fisher's study on the inheritance of continuous traits, after which several methods have been developed (Robinson, 1987; Searle et al., 1992). Henderson's (Henderson, 1953) ANOVA-based methods have been widely used until the study of Hartley and Rao (Hartley \& Rao, 1967) on ML method, which became less popular after Petterson and Thompson (Patterson \& Thompson, 1971) have proposed REML method of estimation. A problem with ANOVA-based methods is that they may give a negative estimate of variance components. On the other hand, ML and REML estimations are non-negative, but biased, whereas integral estimates based on the asymptotic distribution of REML may include negative values (Lin \& McAllister, 1984; Gianola \& Foulley, 1990).

The Bayesian method of estimation is an alternative to the above-mentioned methods and its strengths have been advocated by several researchers from various disciplines, including animal science (Wang et al., 1994; Sorensen et al., 1994; Firat, 1996a; Van Tassell \& Van Vleck 1996). Firat (1996b) described the application of Gibbs sampling using conjugate and non-conjugate prior specifications under a single-trait sire model. From the Bayesian point of view, prior knowledge about the unknown parameters is formally incorporated into the estimation process by assigning prior distributions to these parameters and inferences are derived on posterior distributions of the parameters (Box \& Tiao, 1973; Firat, 1996a). Bayesian methods, as generally referred to Markov Chain Monte Carlo (MCMC) methods, attempt to simulate direct draws from distributions and recently became popular due to the developments in computer technology and flexible software programs.

This study aimed at estimating the heritability of some growth traits of Japanese quail by the estimation of variance components via Bayesian methodology.

\section{MATERIAL AND METHODS}

Birds in this study were managed according to the regulations of the European Convention for the Protection of Animals kept for Farming Purposes.

The present experiment was conducted at the Poultry Breeding Unit, Animal Science Department, Faculty of Agriculture, Akdeniz University, Turkey. Birds were housed in individual cages during the experiment. A sex ratio of 1 male to 3 female was used for mating in the parent stock. In total, 340 progenies of 34 sires were used in the study. The number of chicks per sire was fixed at 10 and experimental birds were randomly selected from 643 fully-pedigreed Japanese quail chicks under this condition. Eggs obtained from individual parent cages were incubated at a temperature of $37.5^{\circ} \mathrm{C}$ and $55 \%$ relative humidity for the first 14 days. They were then transferred to the hatcher located in the bottom of the same incubator individually, and maintained at $37^{\circ} \mathrm{C}$ and $70 \%$ relative humidity until hatching. Chicks were wing-banded on the first day before being transferred to growing battery cages. They were reared as straight-run flocks under standard brooding temperatures. Birds were fed with a starter feed containing $240 \mathrm{~g}$ protein/ $\mathrm{kg}$ and 12 $\mathrm{MJ} / \mathrm{kg}$ metabolizable energy for the first 21 days, and then with a grower feed containing $200 \mathrm{~g}$ protein/ $\mathrm{kg}$ and $11.8 \mathrm{MJ} / \mathrm{kg}$ metabolizable energy until 42nd days of age. Feed and water were supplied ad libitum.

In this study, live weight (LW42) and absolute and relative growth rates (AGR42, RGR42) at 42 days of age were the traits of interest. Therefore, a preliminary step was necessary to estimate the AGR42 and RGR42 of each animal. First, the following Gompertz nonlinear model was fitted to the weekly live weight measurements of each bird from hatching to 42 days of age using SAS 9.2 software NLIN procedure (SAS Institute Inc., 2009):

$$
y_{j}=\beta_{\circ} \times \exp \left(-\beta_{1} \times \exp \left(-\beta_{2} t_{j}\right)\right)
$$

where, $y_{j}$ is the live weight at time $t$ (the age of the quail in days), $\beta_{0}, \beta_{1}$ and $\beta_{2}$ are the parameters to be estimated. Then, AGR42s and RGR42s of each animal were estimated from their parameter estimates as follows (Yang et al., 2006),

$$
\begin{gathered}
A G R 42=\beta_{2} \beta_{0} \beta_{1} \times \exp \left(-\beta_{1} \times \exp \left(-\beta_{2} \times 42\right)\right) \times \exp \left(-\beta_{2} \times 42\right) \\
R G R 42=\beta_{2} \times\left(\ln \left(\beta_{0}\right)-\ln \left(y_{42}\right)\right)
\end{gathered}
$$

The balanced one-way sire model is considered in representing the each observation and is given by

$$
y_{i j}=\mu+s_{i}+e_{i j} \quad i=1, \ldots, s_{i j}=1, \ldots, n
$$

where $y_{i j}$ represents the observation (LW42, AGR42 or RGR42) for $j$ th offspring of $i$ th sire, $\mu$ is the constant inherent to data, $s_{i} \sim N\left(0, \sigma_{s}^{2}\right)$ is the random effect 
associated with ith sire and $e_{i j} \sim\left(0, \sigma_{e}^{2}\right)$ is the residual error term. $\sigma_{s}^{2}$ and $\sigma_{e}^{2}$ are the variance components related to sire and environment effects, respectively.

Given the data, model inferences are based on the joint posterior distribution $p(\theta \mid \mathbf{y})$ where $\mathrm{y}$ is the data and $\theta$ is the vector of unknown parameters, in this case $\theta=\left\{\mu, \mathbf{s}, \sigma_{s}^{2}, \sigma_{e}^{2}\right\}$, where $\mathbf{s}=\left\{s_{1}, \ldots, s_{s}\right\}$ is a vector. Bayes theorem states that posterior distribution is a product of prior distribution for the model parameters,

$p(\theta)$, and the likelihood function, $p(\mathbf{y} \mid \theta)$ (Gianola \& Fernando, 1986):

$$
p(\theta \mid \mathbf{y}) \propto p(\theta) p(\mathbf{y} \mid \theta)
$$

For $\mu$, we assumed a flat-improper prior.

$$
f(\mu) \propto \text { constant }
$$

The normal distributions assigned to $s_{i}$ 's are viewed as prior distributions as well.

$$
f\left(s_{i} \mid \sigma_{s}^{2}\right) \propto\left(\sigma_{s}^{2}\right)^{-\frac{1}{2} s} \exp \left\{-\frac{1}{2 \sigma_{s}^{2}} \sum_{i=1}^{s} s_{i}^{2}\right\}
$$

Prior distributions of variance components are assumed to follow inverse gamma distribution, which is common because it is often the conjugate prior for the variance components under the sire model (Bink et al., 1998).

$$
\begin{aligned}
& f\left(\sigma_{s}^{2} \mid v_{s}, s_{s}^{2}\right) \propto\left(\sigma_{s}^{2}\right)^{-\frac{1}{2}\left(v_{s}+2\right)} \exp \left\{-\frac{v_{s} s_{s}^{2}}{2 \sigma_{s}^{2}}\right\} \\
& f\left(\sigma_{e}^{2} \mid v_{e}, s_{e}^{2}\right) \propto\left(\sigma_{e}^{2}\right)^{-\frac{1}{2}\left(v_{e}+2\right)} \exp \left\{-\frac{v_{e} s_{e}^{2}}{2 \sigma_{e}^{2}}\right\}
\end{aligned}
$$

where $S_{s}^{2}$ and $S_{e}^{2}$ are prior expectations of variance components $\sigma_{s}^{2}$ and $\sigma_{e}^{2}$, respectively; $v_{s}$ and $v_{e}$ are precision parameters analogous to degrees of freedom, reflecting the degree of belief on the prior values of variance components. The likelihood for the model is given by,

$f\left(\mathbf{y} \mid \mu, \mathbf{s}, \sigma_{s}^{2}, \sigma_{e}^{2}\right) \propto\left(\sigma_{e}^{2}\right)^{-\frac{1}{2} s n} \exp \left\{-\frac{1}{2}\left[\frac{\sum_{i=1}^{s} \sum_{j=1}^{n}\left(y_{i j}-\mu-s_{i}\right)^{2}}{\sigma_{e}^{2}}\right]\right\}$

From the joint posterior density (not shown here), the full conditional distributions of the parameters can be obtained by treating the others as constants and having the terms involving the parameter of interest. Hence, the full conditional distributions of the parameters can be summarized as follows,

$$
\begin{aligned}
& \mu \mid \mathbf{s}, \sigma_{s}^{2}, \sigma_{e}^{2}, \mathbf{y} \sim N\left(\frac{\sum_{i=1}^{s} \sum_{j=1}^{n}\left(\bar{y}_{. .}-s_{i}\right)}{n s}, \frac{\sigma_{e}^{2}}{n s}\right), \\
& \mathbf{s} \mid \mu, \sigma_{s}^{2}, \sigma_{e}^{2}, \mathbf{y} \sim N\left(\frac{n \sigma_{s}^{2}\left(y_{i}-\mu\right)}{\sigma_{e}^{2}+n \sigma_{s}^{2}}, \frac{\sigma_{s}^{2} \sigma_{e}^{2}}{\sigma_{e}^{2}+n \sigma_{s}^{2}}\right), \\
& \sigma_{s}^{2} \mid \mu, \mathbf{s}, \sigma_{e}^{2}, \mathbf{y} \sim / G\left(\frac{s+v_{s}}{2}, \frac{\sum_{i=1}^{s} s_{i}^{2}+v_{s} s_{s}^{2}}{2}\right)
\end{aligned}
$$

$\sigma_{e}^{2} \mid \mu, \mathbf{s}, \sigma_{s}^{2}, \mathbf{y} \sim / G\left(\frac{s n+v_{e}}{2}, \frac{\sum_{i=1}^{s} \sum_{j=1}^{n}\left(y_{i j}-\mu-s_{i}\right)^{2}+v_{e} s_{e}^{2}}{2}\right)$

The Bayesian approach is considered and computations were performed using Markov Chain Monte Carlo (MCMC) technique (Robert \& Casella, 2004). Analyses were performed using the MCMCglmm package of $R$ software ( $R$ Development Core Team, 2010; Hadfield, 2010). Each trait was analyzed separately. A single chain of length 65,000 was run for each trait, and after discarding the first 15,000 iterations and saving the every $50^{\text {th }}$ sample, 1,000 posterior samples were stored for each parameter. Parameters for prior distributions of sire and environment variances were obtained from their corresponding REML estimates.

Posterior estimates of the heritabilities for the traits were calculated from the posterior expectations of sire and environment variance components using the formulae given as,

$$
h^{2}=\frac{4 \sigma_{s}^{2}}{\sigma_{s}^{2}+\sigma_{e}^{2}}
$$

\section{RESULTS}

Some descriptive statistics of the traits are presented in Table 1. Live weight at 42 days of age was found to be $200.130 \mathrm{~g}$ in this study. The means of AGR42 and RGR42 were found to be 2.394 and 0.010 , respectively.

Table 1 - Descriptive statistics of the traits

\begin{tabular}{lccccc}
\hline Trait & Mean $(\mathrm{g})$ & Std Dev & CV & Minimum & Maximum \\
\hline LW42 & 200.130 & 22.286 & 11.136 & 104.700 & 255.600 \\
AGR42 & 2.394 & 0.688 & 28.745 & 0.808 & 4.429 \\
RGR42 & 0.010 & 0.003 & 34.539 & 0.001 & 0.031 \\
\hline
\end{tabular}


Autocorrelations among consecutive observations for variance components were low $(r<0.05)$. Posterior distributions of $\mu$ for each trait were normally distributed. Descriptive statistics for the posterior expectations of variance components and heritabilities are given in Table 2 . The most frequently used descriptive statistics for the parameters of interest were the mode, median and the mean of the posterior distribution. However, inferences on parameters may be made by considering their posterior distributions rather than only point estimates. It can be seen that mode, median and mean estimates are similar for environmental variance of AGR42 and RGR42, whereas they are somewhat different for LW42. For sire variance, point estimates tend to differ in all traits considered. Further, the $95 \%$ credible intervals for expected sire variances are asymmetric, being long above the mean as below the mean. Monte Carlo Errors (MCE), which measures the error in parameter estimation, are small, indicating that the length of each chain is sufficient (Van Tassell \& Van Vleck 1996).

Figure 1 summarizes the marginal posterior distributions of the parameters for each trait. Marginal posterior distributions of the heritabilities appear in the right-most panel of Figure 1 and the first two panels

represent the marginal posterior distributions of $\sigma_{s}^{2}$

and $\sigma_{e}^{2}$, respectively. Close examination of the distributions indicates that all marginal posterior densities are unimodal and, as expected, variance components for all traits do not include negative values. Moreover, the densities of heritabilities are close to normality and the marginal posterior distribution of $\sigma_{s}^{2}$ is slightly skewed toward the right.

The estimate of the heritability coefficients tends to differ depending on which point estimate is considered, mode, median or mean (Table 2). However, each leads to the same conclusion. Heritability of LW42 was found to be high. According to our findings, AGR42 may be considered as a moderate heritable trait, whereas RGR42 is low heritable.

\section{DISCUSSION}

Mean value for LW42 is in good agreement with that reported by Baylan et al. (1997) and Narinc et al. (2010a), but higher than that of Saatci et al. (2003) and Shokoohmand et al. (2007). The few studies in Japanese quail have determined absolute and relative growth rates from the growth curve. AGR42 and RGR42 means obtained in the present study were similar to the values (1.90 and 0.0094, respectively) reported by Narinc et al. (2010b). Hyankova et al. (2001) have also reported similar findings (data were shown in figures) for absolute and relative growth rates.

This LW42 heritability estimate is higher than that obtained by Saatci et al. (2006), who reported 0.15. In another study, Shokoohmand et al. (2007) reported heritability estimates for different strains as 0.48 , 0.50 and 0.72. Sezer et al. (2006) reported higher heritability estimate for 42 -d-old males (0.60) and a

Table 2 - Posterior expectations of variance components and heritabilities, and Monte Carlo Errors (MCE) of the estimates

\begin{tabular}{|c|c|c|c|c|c|c|c|c|}
\hline \multirow{2}{*}{ Trait } & \multirow{2}{*}{ Parameter } & \multirow{2}{*}{ Mode } & \multirow{2}{*}{ Median } & \multirow{2}{*}{ Mean } & \multirow{2}{*}{ SD } & \multirow{2}{*}{ MCE } & \multicolumn{2}{|c|}{ Credible Interval (\%) } \\
\hline & & & & & & & 2.5 & 97.5 \\
\hline \multirow{3}{*}{ LW42 } & $\sigma_{s}^{2}$ & 54.665 & 59.508 & 61.187 & 13.365 & 0.415 & 38.949 & 91.569 \\
\hline & $\sigma_{e}^{2}$ & 434.103 & 439.064 & 440.609 & 25.473 & 0.845 & 395.188 & 492.851 \\
\hline & $h^{2}$ & 0.452 & 0.477 & 0.487 & 0.099 & 0.003 & 0.322 & 0.701 \\
\hline \multirow{3}{*}{ AGR42 } & $\sigma_{s}^{2}$ & 0.035 & 0.038 & 0.039 & 0.009 & 0.000 & 0.024 & 0.058 \\
\hline & $\sigma_{e}^{2}$ & 0.438 & 0.438 & 0.439 & 0.025 & 0.001 & 0.393 & 0.490 \\
\hline & $h^{2}$ & 0.289 & 0.316 & 0.323 & 0.069 & 0.002 & 0.207 & 0.478 \\
\hline \multirow{3}{*}{ RGR42 } & $\sigma_{s}^{2}$ & $4.42 \times 10^{-7}$ & $4.45 \times 10^{-7}$ & $4.60 \times 10^{-7}$ & $1.05 \times 10^{-7}$ & $2.92 \times 10^{-9}$ & $2.86 \times 10^{-7}$ & $6.99 \times 10^{-7}$ \\
\hline & $\sigma_{e}^{2}$ & $1.21 \times 10^{-5}$ & $1.19 \times 10^{-5}$ & $1.19 \times 10^{-5}$ & $6.76 \times 10^{-7}$ & $2.31 \times 10^{-8}$ & $1.07 \times 10^{-5}$ & $1.33 \times 10^{-5}$ \\
\hline & $h^{2}$ & $1.43 \times 10^{-1}$ & $1.43 \times 10^{-1}$ & $1.49 \times 10^{-1}$ & $3.42 \times 10^{-2}$ & $9.89 \times 10^{-4}$ & $9.13 \times 10^{-2}$ & $2.26 \times 10^{-1}$ \\
\hline
\end{tabular}



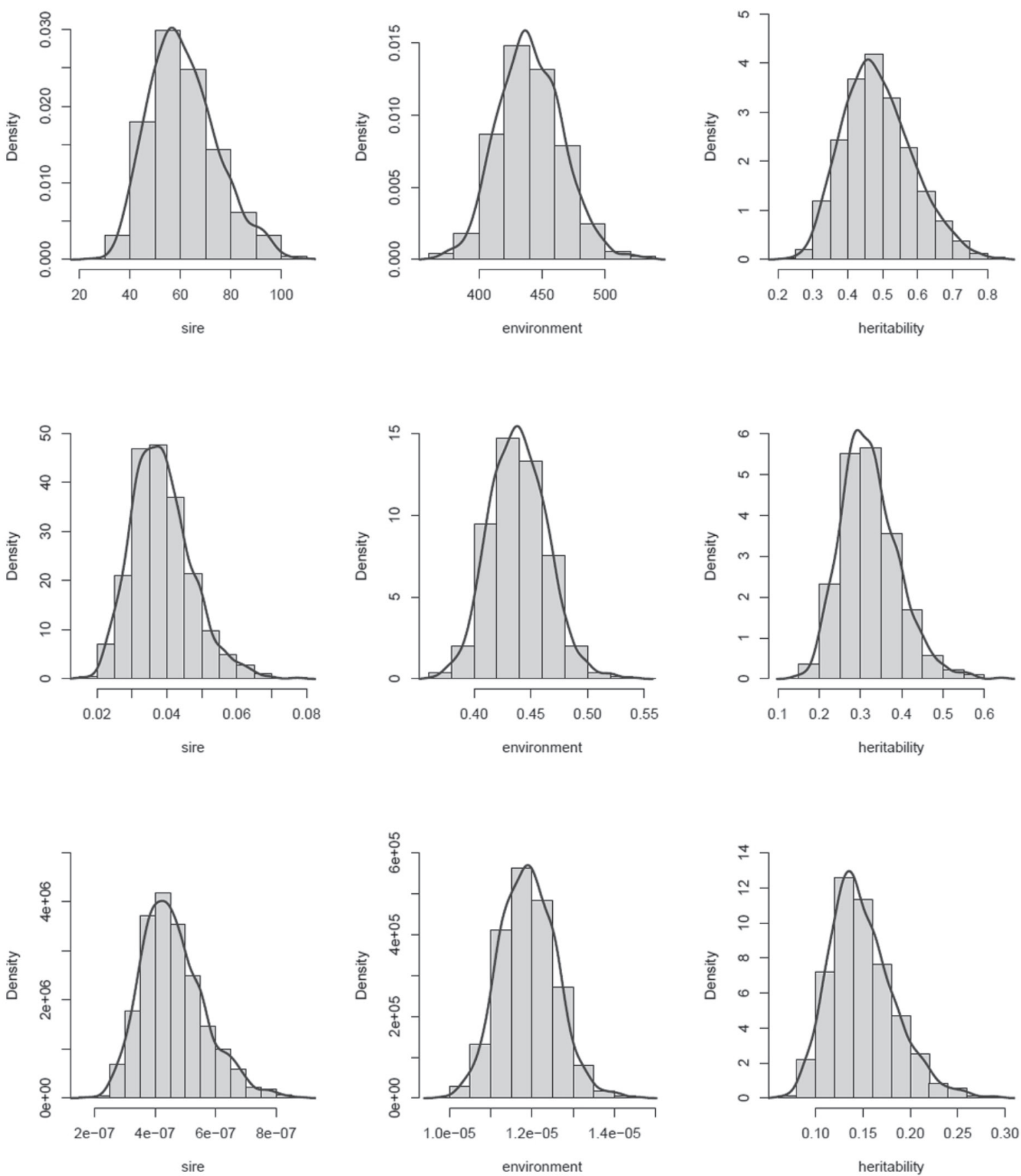

Figure 1 - Marginal posterior distributions of variance componets and heritabilities

lower estimate for females (0.41). Narinc et al. (2010a) reported higher LW42 heritability (0.60), whereas Vali et al. (2005) reported a lower (0.22) value than that found in this study. Narinc et al. (2010b) reported AGR42 and RGR42 heritability estimates of 0.29 and 0.08 , respectively. The difference between these heritability estimates may be attributed to the method of estimation, the model used in the study, bird strain, environmental effects, or sampling errors (Mielenz et al., 2006).
The amount of heritability of a trait does not affect the decision of including it in a breeding program and even low heritable traits can be improved by selection. However, the knowledge on the amount of heritability is needed to decide which selection strategy should be used. If the trait has high heritability, rapid genetic improvement is expected by using individual breeding values. Particularly in poultry breeding, for low heritable traits such as reproduction traits, family selection may result in an increased efficiency of genetic improvement. 


\section{CONCLUSION}

The present study has focused on the Bayesian estimation of variance components and heritabilities of some growth traits that have rarely been considered in breeding studies of Japanese quail. The method of estimation applied in this study includes the prior knowledge on the parameters as well as information based on these data. The method may be used to obtain accurate estimates of parameters, even when data sets are small. Heritability is one of the most important genetic parameters in animal breeding. Single trait analysis may provide general information for breeders to design selection strategies, while multi-trait analyses are preferred as they allow taking into consideration the genetic relationships between traits. On the other hand, the methodology applied in the present study can easily be extended to multi-trait models.

\section{ACKNOWLEDGEMENTS}

This research study, under project number 2011.03.0121.005, was funded by the Akdeniz University Scientific Research Projects Management.

\section{REFERENCES}

Aggrey SE. Modelling the effect of nutritional status on pre-asymptotic and relative growth rates in a random-bred chicken population. Journal Animal Breeding Genetics 2004;121:260-268.

Akbas Y, Yaylak E. Heritability estimates of growth curve parameters and genetic correlations between the growth curve parameters and weights at different age of Japanese quail. Arch. Geflugelk. 2000; 64 (4): 141-146.

Baylan M, Ayasan T, Uluocak AN, Okan F. The effect of sex and age on growing parameters in quail. Proceedings of the Trakya Region II, Animal Symposium, (TRAS'97), Tekirdag 1997;331-334.

Bink MCAM, Quaas RL, Van Aredonk JAM. Bayesian estimation of dispersion parameters with a reduced animal model including polygenic and QTL effects. Genetics Selection Evolution 1998;30:103-125.

Box GEP, Tiao GC. Bayesian inference in statistical analysis. Reading: Addison-Wesley; 1973.

Firat MZ. A comprehensive review of history and use of variance components with special reference to animal breeding. Turkish Journal Veterinary Animal. Sciences 1996a; 20: 343-351.

Firat MZ. Bayesian methods in animal breeding with different prior specification using gibbs sampling. Turkish Journal Veterinary Animal Sciences 1996b;20:359-365.

Gianola D, Fernando RL. Bayesian methods in animal breeding theory. Journal Animal Sciences 1986;63:217-244.

Gianola D, Foulley JL. Variance estimation from integrated likelihoods (VEIL). Genetics Selection Evolution 1990;22:403-417

Hartley HO, Rao JNK. Maximum likelihood estimation for the mixed analyses of variance model. Biometrika 1967;54:93-108.

Hadfield JD. MCMC Methods for Multi-Response Generalized Linear Mixed Models: The MCMCglmm R Package. Journal Statistical Software 2010;33(2):1-22. Avalilable from: URL http://www.jstatsoft.org/v33/ i02/.

Henderson CR. Estimation of variance and covariance components. Biometrics 1953;9(2): 226-252.
Hyankova L, Knizetova H, Dedkova L, Hort J. Divergent selection for shape of growth curve in Japanese quail. 1. Responses in growth parameters and food conversion. British Poultry Science 2001;42:583-589.

Kumar S, Rao AR, Bhatia VK. Bayesian estimation of heritability in animal breeding experiments under 2-way nested classification. Journal Indian Society of Agricultural. Statistics 2004;58(3):352-362.

Lin CY, McAllister AJ. Monte carlo comparison of four methods for estimation of genetic parameters in the univariate case. Journal Dairy Science 1984;67:2389-2398.

Mielenz N, Noor RR, Schuler L. Estimation of additive and non-additive genetic variances of body weight, egg weight and egg production for quail (Coturnix coturnix Japonica) with an animal model analysis. Archiv Tierzucht 2006;49:300-307.

Misztal I. Restricted maximum likelihood estimation of variance components in animal model using sparse matrix inversion and a supercomputer. Journal Dairy Science 1990; 73:163-172.

Narinc D., Aksoy T., Karaman E. Genetic parameters of growth curve parameters and weekly body weights in japanese quail (Coturnix coturnix Japonica). JAVA 2010a; 9(3): 501-507.

Narinc D, Karaman E, Kaya E, Aksoy T. Genetic architecture of absolute and relative growth rates in Japanese quail. Proceedings of the 13 European Poultry Congress;2010b; Tours. France.

Patterson HD, Thompson R. Recovery of interblock information when block sizes are unequal. Biometrika 1971;58:545-551.

R Development Core Team. R: A language and environment for statistical computing, reference index version 2.12.1. Vienna: R Foundation for Statistical Computing; 2010. Available from: URL http://www.Rproject.org.

Remignon H, Le Bihan-Duval E. Meat quality problems associated with selection for increased production. In: Muir WM, Aggrey SE, editors. Poultry genetics, breeding and biotechnology. CABI Publishing; 2010. p.53-66.

Robert CP, Casella G. Monte Carlo statistical methods. $2^{\text {nd }}$ ed. New York: Springer; 2004

Robinson DL. Estimation and use of variance components. The Statistician 1987;36(1):3-14.

Saatci M, Ap Dewi I, Aksoy AR. Application of REML procedure to estimate the genetic parameters of weekly live weights in one-to-one sire and dam pedigree recorded Japanese quail. Journal Of Animal Breeding And Genetics 2003;120:23-28.

Saatci M, Omed H, Ap Dewi I. Genetic parameters from univariate and bivariate analyses of egg and weight traits in Japanese quail. Poultry Science 2006;85:185-190.

SAS Institute. SAS/STAT user's guide. Version 9.2 ed. Cary; 2009.

Searle SR, Casella G, McCulloch CE. Variance components. New Yorj: John Wiley and Sons; 1992.

Sezer M, Berberoglu E, Ulutas Z. Genetic association between sexual maturity and weekly live-weights in laying-type Japanese quail. SAJAS 2006;36:142-148.

Shokoohmand M, Emam Jomeh Kashan N, Emami Maybody MA. Estimation of heritability and genetic correlations of body weight in different age for three strains of Japanese quail. Intternational Journal of. Agriculture and Biology 2007;945-947.

Sorensen DA, Wang CS, Jensen J, Gianola D. Bayesian analysis of genetic change due to selection using gibbs sampling. Genetics Selection Evolution 1994;26:333-360.

Vali N, Edriss MA, Rahmani HR. Genetic parameters of body and some carcass trait in two quail strains. International Journal of Poultry Science 2005; 4:296-300.

Van Tassell CP, Van Vleck LD. Multiple-trait gibbs sampler for animal models: Flexible programs for bayesian and likelihood-based (co)variance component inference. Journal of Animal Science 1996;74:2586-2597.

Wang CS, Gianola D, Sorensen DA, Jensen J, Christensen J, Rutledge JJ. Response to selection for litter size in Danish landrace pigs: A bayesian analysis. Theoretical and Applied Genetics 1994;88:220-230.

Yang Y, Mekki DM, Lv SJ, Wang LY, Yu JH, Wang JY. Analysis of fitting growth models in Jinghai mixed-sex yellow chicken. International Journal of Poultry Science 2006;5(6): 517-521. 